\title{
Local electronic and optical behaviors of a-plane GaN grown via epitaxial lateral overgrowth
}

J. C. Moore

Virginia Commonwealth University

V. Kasliwal

Virginia Commonwealth University

A. A. Baski

Virginia Commonwealth University, aabaski@vcu.edu

See next page for additional authors

Follow this and additional works at: http://scholarscompass.vcu.edu/phys_pubs

Part of the Physics Commons

Moore, J. C., Kasliwal, V., Baski, A. A., et al. Local electronic and optical behaviors of a-plane GaN grown via epitaxial lateral overgrowth. Applied Physics Letters, 90, 011913 (2007). Copyright (C) 2007 AIP Publishing LLC.

\section{Downloaded from}

http://scholarscompass.vcu.edu/phys_pubs/23

This Article is brought to you for free and open access by the Dept. of Physics at VCU Scholars Compass. It has been accepted for inclusion in Physics Publications by an authorized administrator of VCU Scholars Compass. For more information, please contact libcompass@vcu.edu. 
Authors

J. C. Moore, V. Kasliwal, A. A. Baski, X. Ni, Ü. Özgür, and Hadis Morkoç 


\title{
Local electronic and optical behaviors of a-plane GaN grown via epitaxial lateral overgrowth
}

\author{
J. C. Moore, V. Kasliwal, and A. A. Baski ${ }^{\text {a) }}$ \\ Department of Physics, Virginia Commonwealth University, Richmond, Virginia 23284 \\ X. Ni, Ü. Özgür, and H. Morkoç \\ Department of Electrical and Computer Engineering, Virginia Commonwealth University, Richmond, \\ Virginia 23284
}

(Received 11 October 2006; accepted 28 November 2006; published online 5 January 2007)

\begin{abstract}
Conductive atomic force microscopy and near-field optical microscopy (NSOM) were used to study the morphology, conduction, and optical properties of $a$-plane GaN films grown via epitaxial lateral overgrowth (ELO) by metal organic chemical vapor deposition. The AFM images for the coalesced ELO films show undulations, where the window regions appear as depressions with a high density of surface pits. At reverse bias below $12 \mathrm{~V}$, very low uniform conduction (2 pA) is seen in the window regions. Above $20 \mathrm{~V}$, a lower-quality sample shows localized sites inside the window regions with significant leakage, indicating a correlation between the presence of surface pits and leakage sites. Room temperature NSOM studies explicitly showed enhanced optical quality in the wing regions of the overgrown $\mathrm{GaN}$ due to a reduced density of dislocations, with the wings and the windows clearly discernible from near-field photoluminescence mapping. (C) 2007 American Institute of Physics. [DOI: 10.1063/1.2429901]
\end{abstract}

In GaN films, surface terminations of threading dislocations (TDs) with a screw component have been shown to exhibit reverse-bias current leakage, which is problematic for device applications. ${ }^{1-3}$ The majority of research has concentrated on dislocations in the basal plane ( $c$ plane) of $\mathrm{GaN}$, although spontaneous polarization and strain-induced piezoelectric effects produce electric fields that introduce additional design constraints. ${ }^{4,5}$ To overcome this problem, recent studies have focused on nonpolar, $a$-plane GaN films. ${ }^{6-9}$ In particular, the epitaxial lateral overgrowth (ELO) and sidewall ELO of $a$-plane GaN have shown a decrease in TDs for films grown via metal organic chemical vapor deposition ${ }^{10-12}$ (MOCVD) and hydride vapor phase epitaxy. ${ }^{13}$ It has been demonstrated that dislocations may bend out from the window regions during faceted ELO to achieve minimum energy, resulting in a reduced number of TDs terminating on the surface window region. ${ }^{14-16}$ Some of these dislocations may again bend towards the surface in the wings or counterpropagating dislocations from opposing wings may annihilate. However, the dislocation density in the windows generally remains significantly higher than that in the wings. Time-resolved photoluminescence studies have also shown that ELO of $a$-plane GaN results in a significant increase in material quality with a reduction in the influence of substrate-related defects. ${ }^{17,18}$ In this work, we have used both conductive atomic force microscopy (CAFM) and near-field scanning optical microscopy (NSOM) to study the local electrical and optical properties of $a$-plane ELO GaN.

The $a$-plane $(11 \overline{2} 0) \mathrm{GaN}$ films $(1.5 \mu \mathrm{m})$ used for ELO templates in this study were grown by MOCVD on $r$-plane (1102) sapphire substrates at $1050{ }^{\circ} \mathrm{C} .{ }^{19}$ A 100 -nm-thick $\mathrm{SiO}_{2}$ layer was then deposited via plasma-enhanced chemical vapor deposition and patterned with $4-\mu \mathrm{m}$-wide windows oriented parallel to the $[10 \overline{1} 0]$ direction of $\mathrm{GaN}$ (14 or

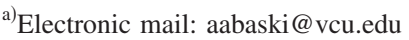

$24 \mu \mathrm{m}$ pitch) using conventional photolithography and buffer oxide etching. To overcome difficulties in coalescence introduced by the wing tilt between the Ga- and N-polar wings, the ELO films were grown in two stages, $2 \mathrm{~h}$ at $1000{ }^{\circ} \mathrm{C}$ (promotes vertical growth) followed by $3 \mathrm{~h}$ at $1050{ }^{\circ} \mathrm{C}$ (promotes lateral growth). ${ }^{20}$ The two samples presented here, which will be referred to as samples 1 and 2, were grown with the same trimethylgallium flow rates $(157 \mu \mathrm{mol} / \mathrm{min})$, but the ammonia flow rate for sample 1 was decreased from 3000 to 600 SCCM (SCCM denotes cubic centimeter per minute at STP) during the second stage, resulting in a higher III/V ratio. Samples 1 and 2 were grown on 24 and $14 \mu \mathrm{m}$ pitch ELO templates, respectively. $\mathrm{X}$-ray diffraction (XRD) data indicate that sample 1 is of slightly lower crystalline quality as compared to sample 2 . When the x-ray beam is oriented parallel to the GaN [10 $\overline{1} 0]$ direction, the full width at half maximum (FWHM) values of the $(11 \overline{2} 0)$ reflection are $0.27^{\circ}$ (sample 1 ) and $0.21^{\circ}$ (sample 2 ). When the beam is oriented along the $\mathrm{GaN} c$ axis, the FWHM values of the most intense $(11 \overline{2} 0)$ reflection (from the Ga wings) are $0.38^{\circ}$ (sample 1) and $0.36^{\circ}$ (sample 2).

For CAFM data acquisition, Ohmic contacts were formed on all samples using $\mathrm{Ti} / \mathrm{Al} / \mathrm{Ti} / \mathrm{Au}$ metallization, and a microscopic Schottky contact was formed between the metallized CAFM tip and the sample. Data were acquired using a Veeco Dimension 3100 AFM with Ti/Pt-coated cantilevers and a current amplifier module with a range of $1 \mathrm{pA}-1 \mu \mathrm{A}$. During imaging, contact-mode topographs were acquired simultaneously with CAFM current images. For high voltage studies $(>12 \mathrm{~V})$, an external bias voltage was applied to the sample via a selectable battery source $(1.5-60 \mathrm{~V})$. NSOM measurements were performed using a Cryoview 2000 system (Nanonics Imaging Ltd.) at room temperature in the illumination mode, where a $325 \mathrm{~nm} \mathrm{HeCd}$ laser was used for excitation through a metal coated cantilevered optical fiber probe with a $350 \mathrm{~nm}$ aperture. NSOM 


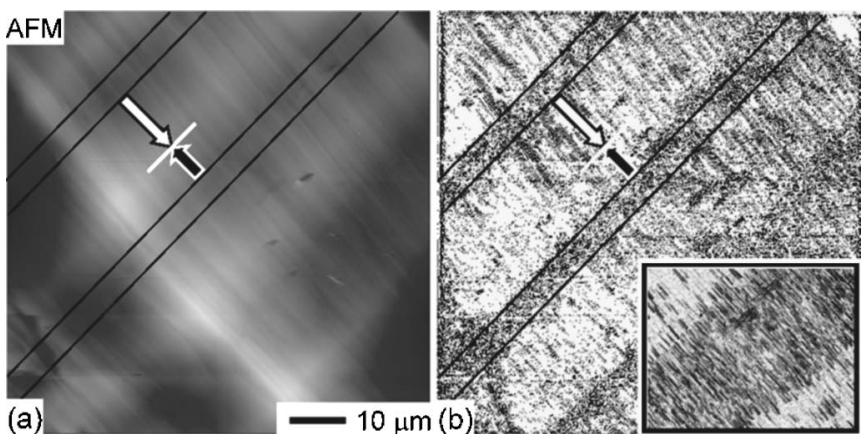

FIG. 1. (a) AFM topography image $\left(75 \times 75 \mu \mathrm{m}^{2}, \Delta z=500 \mathrm{~nm}\right)$ of sample 1 with window regions outlined by black lines. White (or black) arrows indicate the locations of Ga-face (or $\mathrm{N}$-face) wing regions. (b) Image shown in (a) after processing to enhance the edges of pits occurring in the window regions (dark areas). (Inset) Higher-resolution, processed image showing the dark pits in a window region.

photoluminescence (PL) intensity mapping was carried out using a photomultiplier tube to collect the overall PL spectrum with the scattered and reflected laser light blocked using an optical filter.

AFM data indicate that both samples have step bunching that produces striations along the $c$ direction, as well as undulations perpendicular to the $c$ direction with depressions in the window regions. Figure 1(a) is an AFM image of sample 1 with the boundaries of two window regions indicated by black lines. To enhance features in the window region, Fig. 1(b) is a high-pass filtered image of Fig. 1(a) with a Sobel edge enhancement applied that produces dark pixels at edge features. The window regions appear as dark bands in the processed image, indicating a high density of edges. These edges occur at surface pits which are seen at higher resolution in the inset of Fig. 1(b). The Ga- and N-polar wings between the windows have significantly fewer pits and are slightly raised at their meeting front. This ridge results from the miscut of the $r$-plane sapphire substrate towards its $c$ axis and the tilt of the two wings. ${ }^{19}$ The meeting front is also off-center between the windows, where the widths of the Ga-polar (white arrow) and N-polar (black arrow) wings have a ratio of approximately $2: 1$, as indicated by AFM, NSOM, and scanning electron microscopy data. The ratio of the wing widths indicates that the Ga-polar wing grows approximately two times faster than the N-polar wing. This difference in growth rates between the Ga- and N-polar surfaces is sensitive to growth temperature, and has been attributed to differences in adsorption and desorption rates ${ }^{11}$ and/or relative chemical stability of the two polarities. ${ }^{20}$

The local conduction behavior of samples 1 and 2 at high reverse bias is presented in Fig. 2, with simultaneous contact-mode AFM and CAFM images shown for each sample. At reverse-bias voltages below $10-15 \mathrm{~V}$, some very low $(2 \mathrm{pA})$ conduction is seen in the window regions on both samples, but more interesting behavior is observed at higher bias. Above $20 \mathrm{~V}$, localized regions with higher current leakage begin to appear in the window regions of sample 1, but not on sample 2. Figure 2(b) is a CAFM image of sample 1 taken at $48 \mathrm{~V}$ reverse bias, which indicates a relatively uniform density of leakage defect sites $\left(3 \times 10^{7} \mathrm{~cm}^{-2}\right)$ with currents ranging from 10 to $500 \mathrm{pA}$. This type of localized leakage is similar to previously reported conduction behavior for defect regions on non-ELO, $c$-plane GaN films. ${ }^{21-24}$ Interestingly, the meeting front on sample 1 also shows a few iso-
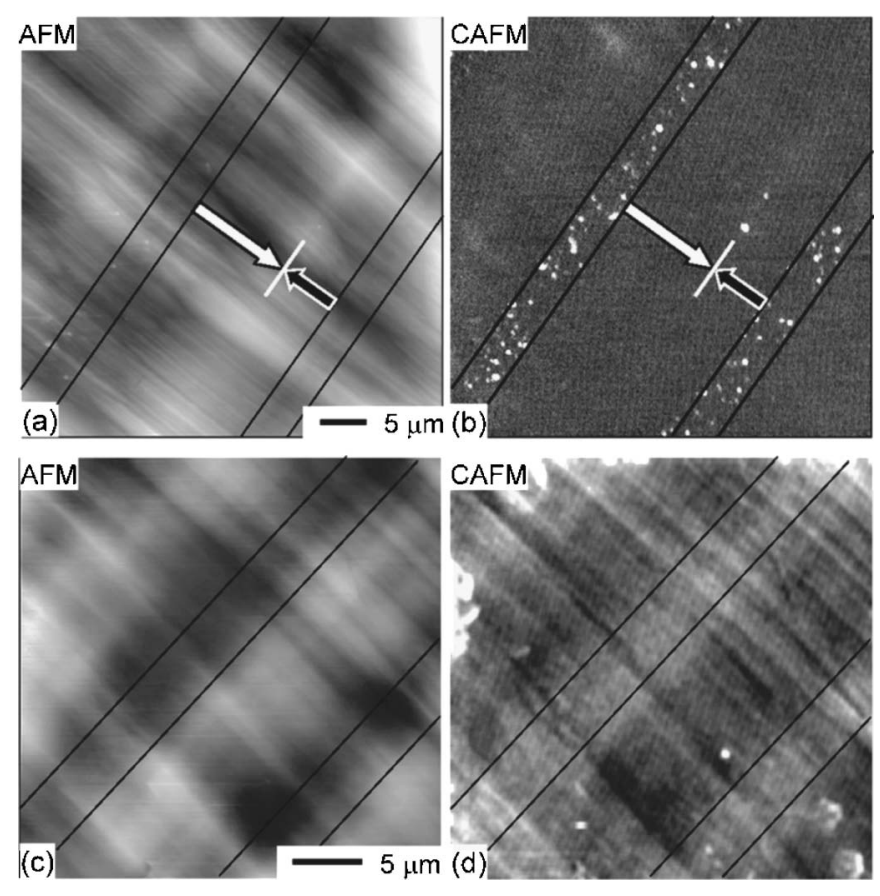

FIG. 2. (a) Contact-mode AFM image of sample $1\left(45 \times 45 \mu \mathrm{m}^{2}\right.$, $\Delta z=300 \mathrm{~nm}$ ) and (b) corresponding CAFM current image at reverse bias $(48 \mathrm{~V}, \Delta I=20 \mathrm{pA})$. (c) AFM image of sample $2\left(30 \times 30 \mu \mathrm{m}^{2}\right.$, $\Delta z=200 \mathrm{~nm}$ ) and (d) corresponding CAFM image (43 V, $\Delta I=2 \mathrm{pA})$. Black lines outline window regions and white (or black) arrows indicate Ga-face (or $\mathrm{N}$-face) wing regions.

lated leakage sites [see vicinity of arrows in Fig. 2(b)]. The location of leakage sites in the window regions and at meeting fronts indicates lower sample quality, i.e., a higher density of defects, in these locations. It has been suggested that surface pits could be decorating dislocations terminated on the surface ${ }^{25}$ and therefore exhibit high leakage current. Such defect sites are only infrequently observed on sample 2 , indicating that sample 2 is of higher quality than sample 1 , which is consistent with XRD results. Because sample 1 was grown with a higher III/V ratio in the second growth stage, its lower quality may be attributed to higher Ga incorporation at threading dislocations. Previous CAFM studies have suggested that $\mathrm{Ga}$ incorporation is the mechanism responsible for reverse-bias leakage at defect sites. ${ }^{1}$

NSOM data of samples 1 and 2 also show a contrast variation in PL intensity between the window and wing regions, as well as a qualitative difference between the two samples. Simultaneous AFM and NSOM data for samples 1 and 2 are provided in Figs. 3(a)-3(d), respectively. Both samples show a weaker average PL intensity in window regions (outlined by black lines) and at meeting fronts (white lines), and a relatively strong intensity on the Ga wings (white arrows). Part of the observed PL intensity decrease at the meeting fronts may be related to a probe-size-related artifact; however, the PL intensity variations in the window and the wing regions are intrinsic to the samples. The increased PL intensity in the wing regions has its origin in the reduction of dislocations, which act as nonradiative recombination channels. The reduction of the dislocation density in the wings has been verified by transmission electron microscopy measurements, ${ }^{20}$ which also indicate additional dislocations generated at the meeting fronts. Therefore, the PL intensity is expected to be higher in the wings than in the windows and at the meeting fronts. There is a distinct differ- 

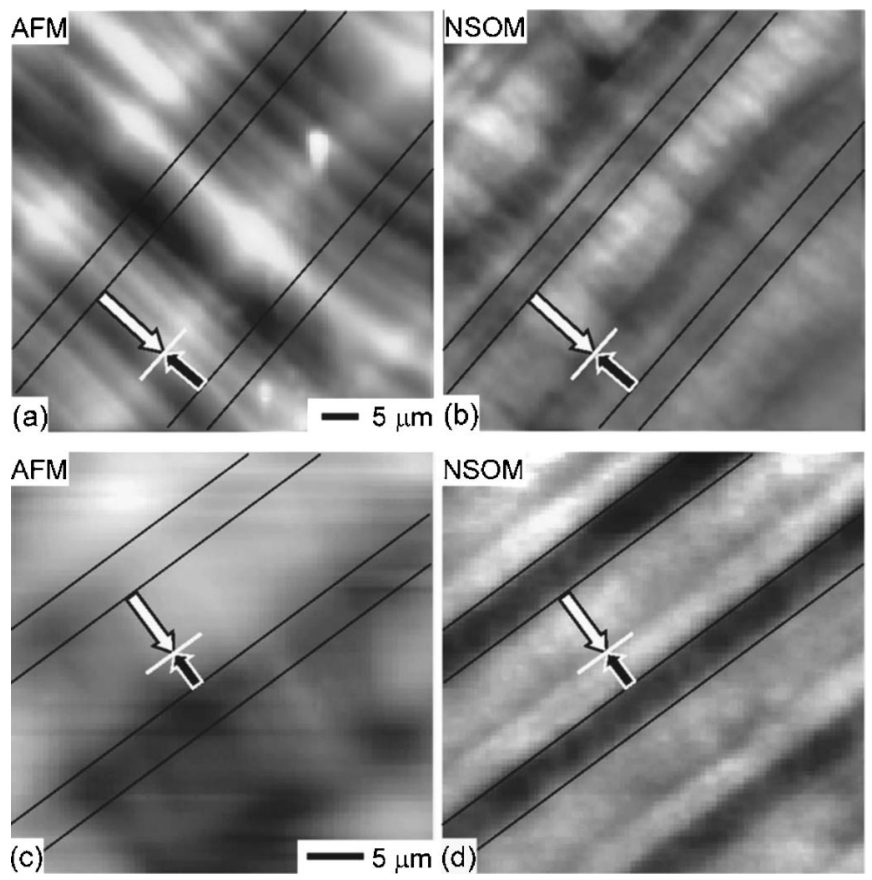

FIG. 3. (a) AFM image $\left(60 \times 60 \mu \mathrm{m}^{2}, \Delta z=150 \mathrm{~nm}\right)$ and (b) simultaneous NSOM PL-intensity image for sample 1 . (c) AFM image $\left(35 \times 35 \mu \mathrm{m}^{2}\right.$, $\Delta z=200 \mathrm{~nm}$ ) and (d) NSOM image of sample 2.

ence between the two samples, however, with regard to the PL intensity on the $\mathrm{N}$ wings. As compared to the $\mathrm{Ga}$ wings, the $\mathrm{N}$-wings demonstrate a weaker intensity on sample 1 and a comparable intensity on sample 2 , suggesting that the optical quality of the $\mathrm{N}$ wings is poor for sample 1 . Additionally, the average PL intensity from the Ga wings is more than six times higher for sample 2 as compared to sample 1 . An independent measurement of the band edge PL intensity using a $\mathrm{HeCd}$ laser $(325 \mathrm{~nm})$ and spectrometer was also an order of magnitude higher for sample 2 . These results indicate that the material quality is poorer for sample 1 , consistent with the results from XRD and CAFM.

In summary, AFM, CAFM, and NSOM data all show a contrast difference between window and wing regions for $a$-plane $\mathrm{GaN}$ grown via ELO. Window regions appear as depressions with a high density of surface pits, with the lower-quality sample 1 showing localized sites inside the window regions with significantly high reverse-bias current leakage. Reduced near-field PL data in window regions also suggest a greater density of surface terminated dislocations in those regions, while wing regions explicitly show enhanced optical quality of the overgrown GaN due to a reduced density of dislocations. The combination of CAFM and NSOM data therefore indicates a correlation between the presence of surface pits, localized reverse-bias current leakage, and low PL intensity.

This work is supported by the National Science Foundation (program monitor: V. Hess) and Air Force Office of Scientific Research (program monitor: K. Reinhardt).

${ }^{1}$ J. W. P. Hsu, M. J. Manfra, S. N. G. Chu, C. H. Chen, L. N. Pfeiffer, and R. J. Molnar, Appl. Phys. Lett. 78, 3980 (2001).

${ }^{2}$ J. W. P. Hsu, M. J. Manfra, D. V. Lang, S. Richter, S. N. G. Chu, A. M. Sergent, R. N. Kleiman, L. N. Pfeiffer, and R. J. Molnar, Appl. Phys. Lett. 78, 1685 (2001).

${ }^{3}$ B. S. Simpkins, D. M. Schaadt, E. T. Yu, and R. J. Molnar, J. Appl. Phys. 91, 9924 (2002).

${ }^{4}$ R. Langer, J. Simon, V. Ortiz, N. T. Pelekanos, A. Barski, R. Andre, and M. Godlewski, Appl. Phys. Lett. 74, 3827 (1999).

${ }^{5}$ T. Deguchi, K. Sekiguchi, A. Nakamura, T. Sota, R. Matsuo, S. Chichibu, and S. Nakamura, Jpn. J. Appl. Phys., Part 2 38, L914 (1999).

${ }^{6}$ H. M. Ng, Appl. Phys. Lett. 80, 4369 (2002).

${ }^{7}$ M. D. Craven, S. H. Lim, F. Wu, J. S. Speck, and S. P. DenBaars, Appl. Phys. Lett. 81, 469 (2002).

${ }^{8}$ A. Chitnis, C. Chen, V. Adivarahan, M. Shatalov, E. Kuokstis, V. Mandavilli, J. Yang, and M. A. Khan, Appl. Phys. Lett. 84, 3663 (2004).

${ }^{9}$ A. Chakraborty, K. C. Kim, F. Wu, J. S. Speck, S. P. DenBaars, and U. K. Mishra, Appl. Phys. Lett. 89, 041903 (2006).

${ }^{10}$ M. D. Craven, S. H. Lim, F. Wu, J. S. Speck, and S. P. DenBaars, Appl. Phys. Lett. 81, 1201 (2002).

${ }^{11}$ C. Q. Chen, J. W. Yang, H. M. Wang, J. P. Zhang, V. Adivarahan, M. Gaevski, E. Kuokstis, Z. Gong, M. Su, and M. A. Khan, J. Chem. Soc., Chem. Commun. 42, L640 (2003).

${ }^{12}$ B. M. Imer, F. Wu, S. P. DenBaars, and J. S. Speck, Appl. Phys. Lett. 88, 061908 (2006).

${ }^{13}$ B. A. Haskell, F. Wu, M. D. Craven, S. Matsuda, P. T. Fini, T. Fujii, K. Fujito, S. P. DenBaars, J. S. Speck, and S. Nakamura, Appl. Phys. Lett. 83, 644 (2003).

${ }^{14}$ S. Gradecak, P. Stadelmann, V. Wagner, and M. Ilegems, Appl. Phys. Lett. 85, 4648 (2004).

${ }^{15}$ Z. Liliental-Weber and D. Cherns, J. Appl. Phys. 89, 7833 (2001).

${ }^{16}$ B. Beaumont, P. Vennéguès, and P. Gibart, Phys. Status Solidi B 227, 1 (2001).

${ }^{17}$ S. Jursenas, E. Kuakstis, S. Miasojedovas, G. Kurilcik, A. Zukauskas, C. Q. Chen, J. W. Wang, V. Adivarahan, and M. A. Khan, Appl. Phys. Lett. 85, 771 (2004).

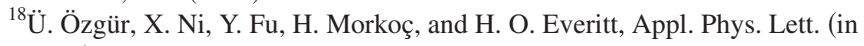
press).

${ }^{19}$ X. Ni, Y. Fu, Y. T. Moon, N. Biyikli, and H. Morkoç, J. Cryst. Growth 290, 166 (2006).

${ }^{20}$ X. Ni, Ü Özgür, Y. Fu, N. Biyikli, J. Xie, A. A. Baski, H. Morkoç, and Z. Liliental-Weber, Appl. Phys. Lett. 89, 262105 (2006).

${ }^{21}$ J. W. P. Hsu, M. J. Manfra, R. J. Molnar, B. Heying, and J. S. Speck, Appl. Phys. Lett. 81, 79 (2002).

${ }^{22}$ B. S. Simpkins, E. T. Yu, P. Waltereit, and J. S. Speck, Mater. Res. Soc. Symp. Proc. 743, L2.4 (2003).

${ }^{23}$ J. Spradlin, S. Dogan, J. Xie, R. Molnar, A. A. Baski, and H. Morkoç, Appl. Phys. Lett. 84, 4150 (2004).

${ }^{24}$ J. C. Moore, K. A. Cooper, J. Xie, H. Morkoç, and A. A. Baski, Proc. SPIE 6121, 61210J-1 (2006).

${ }^{25}$ D. N. Zakharov, Z. Liliental-Weber, B. Wagner, Z. J. Reitmeier, E. A. Preble, and R. F. Davis, Phys. Rev. B 71, 235334 (2005). 